DR. EDUARDO BERNABE (Orcid ID : 0000-0002-1858-3713)

PROF. ANNA LIISA LIISA SUOMINEN (Orcid ID : 0000-0002-8543-0055)

Article type : Original Article

\title{
Interdental Cleaning and Periodontal Pocketing among Finnish Adults
}

\section{Eduardo BERNABÉ, ${ }^{1}$ Matti KNUUTTILA, ${ }^{2}$ Anna L. SUOMINEN ${ }^{3,4,5}$}

${ }^{1}$ Faculty of Dentistry, Oral \& Craniofacial Sciences, King's College London, London, United Kingdom

${ }^{2}$ Medical Research Center, Oulu University Hospital and University of Oulu, Oulu, Finland

${ }^{3}$ Department of Oral Public Health, Institute of Dentistry, University of Eastern Finland, Kuopio, Finland

${ }^{4}$ Public Health Evaluation and Projection Unit, National Institute for Health and Welfare (THL), Helsinki, Finland

${ }^{5}$ Department of Oral and Maxillofacial Diseases, Kuopio University Hospital, Kuopio, Finland

Running title: interdental cleaning and pocketing

Keywords: periodontal diseases; periodontitis; oral hygiene; Dental devices, home care; cohort studies; adults

This article has been accepted for publication and undergone full peer review but has not been through the copyediting, typesetting, pagination and proofreading process, which may lead to differences between this version and the Version of Record. Please cite this article as doi: $10.1111 /$ jcpe. 13081

This article is protected by copyright. All rights reserved. 


\section{Corresponding Author:}

Dr. Eduardo Bernabé, Dental Public Health, King's College London Dental Institute, Denmark Hill Campus, Bessemer Road, London SE5 9RS, United Kingdom

Tel: +44 (0) 203299 3022; email: eduardo.bernabe@kcl.ac.uk

\section{Conflict of Interest and Source of Funding Statement}

No external funding, apart from the support of the authors' institution, was available for this study. The authors declare that there are no conflicts of interests in this study.

\section{Abstract}

Aim: To investigate the relationship between frequency of interdental cleaning and 11-year change in teeth with periodontal pocketing in Finnish adults.

Methods: Data from 1667 dentate adults, aged 30 to 82 years, who participated in the Health 2000 survey and were re-examined in 2004 and/or 2011 were analysed. Participants reported their frequency of interdental cleaning (either dental floss or interdental brush) at baseline. Teeth with periodontal pocketing $(\mathrm{PD}) \geq 4 \mathrm{~mm}$ were counted in every survey and treated as a repeated outcome. The association between the frequency of interdental cleaning and the number of teeth with $\mathrm{PD} \geq 4 \mathrm{~mm}$ was evaluated in linear mixed effects models, controlling for demographic factors, socioeconomic position, diabetes, smoking status, toothbrushing frequency, dental attendance and number of teeth.

Results: Twelve percent of adults reported daily interdental cleaning. Significant inverse linear trends in the number of teeth with $\mathrm{PD} \geq 4 \mathrm{~mm}$ were found in every survey according to the frequency of interdental cleaning. However, this association was completely attenuated after adjustment for the full set of confounders. Contrarily, toothbrushing frequency was negatively associated with the baseline number of teeth with $\mathrm{PD} \geq 4 \mathrm{~mm}$ and its rate of change over time. 
Conclusion: Interdental cleaning was not associated with 11-year change in periodontal pocketing after accounting for other established risk factors for periodontal disease.

\section{Clinical Relevance}

Scientific rationale for study: The value of interdental cleaning for the prevention of periodontal disease is still unclear.

Principal findings: This population-based prospective study, which only examined pocket depth, shows interdental cleaning was not associated with changes in periodontal pocketing. Toothbrushing was inversely associated with changes in periodontal pocketing.

Practical implications: Interdental cleaning had no additional value to regular toothbrushing for the prevention of periodontal pocketing in the general population.

\section{Introduction}

Periodontitis is a chronic inflammatory plaque-related disease characterised by the progressive destruction of the tooth- supporting structure (Papapanou et al., 2018, Caton et al., 2018). Mechanical disruption of the biofilm, via toothbrushing and interdental cleaning, is considered an important strategy for the management of dental caries and gingivitis (Jepsen et al., 2017, Chapple et al., 2015). Interdental cleaning, using either floss or interdental brushes, is advocated to clean interproximal areas between adjacent teeth that a regular toothbrush cannot reach efficiently (Salzer et al., 2015). Flossing at least once daily is the most common recommendation for interdental cleaning (ADA, 2014, PHE/DoH, 2017).

It is now well established that toothbrushing prevents dental caries, especially when used as a means to deliver fluoride toothpaste (Kumar et al., 2016), and periodontal disease (Zimmermann et al., 2015). However, the same cannot be said with regard to interdental cleaning. There is insufficient, mostly weak evidence on the value of flossing and interdental brushing when compared to toothbrushing alone for plaque removal and the maintenance of gingival health (Sambunjak et al., 2011, Poklepovic et al., 2013, Salzer et al., 2015). Rather than not proven effective, some have argued that there is no high-quality evidence from robust prospective studies to evaluate if interdental cleaning prevents periodontal disease (Vernon et al., 2017, Vernon and Seacat, 2017). 
Given that a clinical trial with a long follow-up period would be needed to observe changes in standard periodontal measurements (such as pocket depth or clinical attachment loss), longitudinal observational studies may provide useful evidence on this important area. Using data from an ongoing cohort, this study explored the association between frequency of interdental cleaning and the 11-year change in teeth with periodontal pocketing in adults.

\section{Materials and Methods}

This report follows the Strengthening the Reporting of Observational Studies in Epidemiology (STROBE) guidelines. The study was not specifically designed to address the research question but rather it was based on secondary analysis of existing data.

\section{Data source}

We pooled together data from three surveys in Finland (Figure 1). The Health 2000 Survey (BRIF8901) was a nationally-representative survey of 8028 adults, aged 30 years or more, selected using stratified two-stage cluster sampling (Aromaa and Koskinen, 2004). Of them, 6335 were dentally examined and 5255 were found to have one or more teeth. In 2004-05, 2000 adults were randomly selected from those who were dentally examined in 2000. After excluding participants who died or were edentate, and those living in health centre districts where $<15$ participants were recruited in 2000, the final sampling frame included 1248 adults who were invited to a new dental examination and 1049 participated. For the Health 2011 Survey, all participants of the Health 2000 Survey alive and in Finland were invited. Only participants living in Southern or Northern Finland ( 2 of the 5 examination areas, $n=3713$ ) were invited to participate in a new dental examination and 1496 agreed (Lundqvist and Mäki-Opas, 2016). The surveys were approved by the Ethics Committee at the Hospital District of Helsinki and Uusimaa. All participants signed a written informed consent before participation.

Overall, 1788 dentate adults had periodontal data for a minimum of two of the three surveys. Of them, $121(7 \%)$ had missing data on relevant variables (education=8, smoking status=8, diabetes $=42$, toothbrushing $=76$, interdental cleaning $=85$, dental attendance $=74$ ) and were thus excluded. Periodontal data were available for 1667 adults in 2000, 840 in 2004 and 1031 in 2011. In addition, 1463 (88\%) adults had periodontal data for two surveys and 204 (12\%) for all three surveys. The follow-up time was 10.8 years, ranging from 10.2 to 11.2 years. 


\section{Variables selection}

Interdental cleaning at baseline was the main exposure of interest. A single question asked participants about their frequency of interdental cleaning (use of dental floss or interdental brush) with four response options (daily, weekly, less frequently and not at all). Demographic characteristics (sex and age), socioeconomic position (education), health status (diabetes) and behaviours (toothbrushing frequency, smoking status and dental attendance pattern), all measured at baseline, were included in the analysis as confounders. Education was indicated by the highest qualification and participants classified as having completed basic, secondary or higher education. Diabetes was derived from multiple sources, either a positive response to the question 'has a doctor ever diagnosed you with diabetes?' or a fasting plasma glucose test $\geq 7.0 \mathrm{mmol} / \mathrm{l}$. Toothbrushing frequency was collected using five options (more than twice daily, twice daily, once daily, less often than daily and never). As no participants in the study sample reported never brushing, analysis was based on the four remaining groups. Smoking status was defined according to four questions taken from the WHO (1998) questionnaire. Current smokers were those who reported that they smoked at least 100 times in their lifetime, they smoked regularly (daily for at least one year), and they last smoked today or the day before. Former smokers were those who reported that they smoked at least 100 times in their lifetime but did not smoke during the last year. Dental attendance pattern was reported using three options (regularly for check-ups, only when in trouble or never). Due to the small number of participants reporting never visiting the dentist $(n=17)$, they were merged with those reporting only when in trouble. Self-reports on interdental cleaning and toothbrushing were validated against dental plaque levels at baseline. Dental plaque was assessed at three tooth surfaces (buccal surface of the most posterior tooth in the first sextant, lingual surface of the most posterior tooth in the fourth sextant, and the buccal surface of the lower left canine), with the highest of three categories (no visible plaque, visible plaque in gingival margin, visible plaque also elsewhere) being recorded. Significant positive trends in plaque levels were found by interdental cleaning and toothbrushing frequency (Table 1).

Dental examinations were conducted at every survey following the same protocol. They were carried out by 5 dentists in 2000, 1 in 2004/05 and 4 in 2011. Dentists examined participants while they were reclined on a portable dental chair, and using mouth mirror, WHO periodontal probe, headlamp and fibre optic light. The periodontal examination was based on the measurement of pocket depth (PD) at four sites per tooth (distobuccal, mid-buccal, mesiolingual and mid-lingual). Only the deepest site per tooth was recorded according to 
three bands $(0-3,4-5,6+\mathrm{mm})$. Third molars and root remnants were excluded. All dentists were trained and calibrated before the surveys. Under field conditions in 2000, Kappa statistics for inter- and intra-examiner reliability were 0.41 and 0.83 at tooth level, respectively (Suominen-Taipale et al., 2004, Suominen-Taipale et al., 2008). The number of teeth with $\mathrm{PD} \geq 4 \mathrm{~mm}$ for each participant was calculated in every survey and used as a repeated outcome measure (Joshi et al., 2018). The $4 \mathrm{~mm}$ cut-off point reflects shallow pocketing and is the lower of two thresholds recommended for reporting PD data in epidemiological studies (Holtfreter et al., 2015, WHO, 2013).

\section{Statistical analysis}

Analyses were carried out using Stata SE version 15 (StataCorp LP, College Station, TX). The associations of interdental cleaning and toothbrushing with the number of teeth with $\mathrm{PD} \geq 4 \mathrm{~mm}$ in every survey were first examined. Student's t-test was used to compare the number of teeth with $\mathrm{PD} \geq 4 \mathrm{~mm}$ by sex, diabetes and dental attendance pattern whereas the analysis of variance (ANOVA) was used to compare the number of teeth with $\mathrm{PD} \geq 4 \mathrm{~mm}$ by age groups, education, smoking status, toothbrushing, interdental cleaning and number of teeth. Age and number of teeth were treated as categorical for these bivariable presentations only.

A linear mixed effects (LME) model was fitted to model the 11-year change in teeth with $\mathrm{PD} \geq 4 \mathrm{~mm}$ using the three periodontal assessments. LME models can model correlated (repeated) outcome measures with missing data and unevenly spaced measurement occasions (Singer and Willett, 2003, Twisk, 2013). Upon preliminary inspection of the data, two time indicators were chosen to model the non-linear nature of the average growth trajectory (i.e. a peak noted in the second survey). The first indicator was continuous age (centred at 46.9 years, the average age at baseline). The intercept and slope were fitted as random effects to model individual variation in baseline value and rate of change in teeth with $P D \geq 4 \mathrm{~mm}$, respectively. The second indicator was a fixed-effect variable with two categories (coded 1 for the second survey and 0 otherwise) called survey, to capture the increase in number of teeth with $\mathrm{PD} \geq 4 \mathrm{~mm}$ that was seen in the second survey. For sensitivity analysis, we used data from 2000 and 2011 only $(n=1078)$ to assess the impact of removing the peak observed in 2004/05. The covariance matrix was estimated without imposing any constraints (unstructured). 
A null model with both time indicators was first fitted to estimate the rate of change in teeth with $\mathrm{PD} \geq 4 \mathrm{~mm}$. Then, the association of interdental cleaning with the 11-year change in teeth with $\mathrm{PD} \geq 4 \mathrm{~mm}$ was tested in sequential models. The main effects model included terms for all baseline predictors (sex, education, diabetes, smoking status, toothbrushing, interdental cleaning, dental attendance pattern and continuous number of teeth). All predictors were treated as time-invariant for analysis. In this model, the parameter associated with each predictor estimates its effect on the baseline number of teeth with $\mathrm{PD} \geq 4 \mathrm{~mm}$. Then, the association of each predictor with the change in teeth with $\mathrm{PD} \geq 4 \mathrm{~mm}$ over time was tested by including their interaction (product term) with each time indicator to the main effects model. These interactions estimate the effect of the predictor on the change in teeth with $\mathrm{PD} \geq 4 \mathrm{~mm}$ over 11 years. The likelihood ratio test (LRT) was used to evaluate whether the addition of the interaction terms to the main effects model improved the goodness-of-fit of the model. The null hypothesis for the LRT assumes that the interaction terms are equal to zero and that the model containing only the main effects of predictors should be preferred. The final LME model consisted of all main effects and any significant interactions with time. To aid interpretation of the significant interactions, predicted mean number of teeth with $\mathrm{PD} \geq 4 \mathrm{~mm}$ at every survey (i.e. trajectories over time) were computed from the final LME model stratified according to the categories of the predictor.

\section{Results}

The study sample consisted of 54\% women and middle-age adults (mean 46.9 years, SD: 10.9, range: 30-82). Participants excluded for missing data were older, reported less frequent toothbrushing and interdental cleaning, and had fewer teeth. An average of 4.0 (SD: 5.5, range: 0-28, adults without any $\mathrm{PD} \geq 4 \mathrm{~mm}: 37.1 \%), 6.4$ (5.7, 0-27, 16.9\%), and 4.6 (5.8, 0-28, $34.0 \%$ ) teeth with $\mathrm{PD} \geq 4 \mathrm{~mm}$ were found in the first, second and third surveys, respectively. An average of 1.0 teeth (SD: 2.1) were lost over the follow-up. Furthermore, $69.0 \%$ and $29.4 \%$ of adults brushed their teeth at least twice daily and reported weekly interdental cleaning. Toothbrushing was more common among female, more educated and non-diabetic adults as well as among those with more teeth and reporting regular dental check-ups. Interdental cleaning was more common among females, more educated participants and never smokers as well as among those with more teeth and reporting regular dental check-ups (Table 2). Toothbrushing and interdental cleaning were positively correlated (Spearman's rho: $0.25, \mathrm{p}<0.001)$. 
Table 3 shows crude associations of every predictor with the number of teeth with $P D \geq 4 \mathrm{~mm}$. At every survey, significant inverse linear trends in the number of teeth with $\mathrm{PD} \geq 4 \mathrm{~mm}$ were found according to interdental cleaning and toothbrushing whereas significant direct trends were found according to number of teeth and smoking status. Men also had more teeth affected than women in every survey. Age and diabetes were directly associated whereas education was negatively associated with number of teeth with $\mathrm{PD} \geq 4 \mathrm{~mm}$, albeit not in every survey.

The null LME model showed an increase of 0.05 (95\%CI: 0.03, 0.07) teeth with PD $\geq 4 \mathrm{~mm}$ per additional year in the average age of participants. A positive covariance was found between intercept and slope $(0.11 ; 95 \% \mathrm{CI}$ : 0.05, 0.18), implying that the steepest positive increment over time was found among those with the highest baseline number of teeth with $\mathrm{PD} \geq 4 \mathrm{~mm}$. The additional binary time indicator was also significant, suggesting an increase of 2.21 (95\% CI: 1.85, 2.56) teeth with $\mathrm{PD} \geq 4 \mathrm{~mm}$ in 2004. According to the main effects model, interdental cleaning was not associated with the number of teeth with $\mathrm{PD} \geq 4 \mathrm{~mm}$ at baseline (Table 4). On the contrary, toothbrushing was inversely associated with the baseline number of teeth with $\mathrm{PD} \geq 4 \mathrm{~mm}$, and it was also inversely associated with the rate of change in teeth with $\mathrm{PD} \geq 4 \mathrm{~mm}$ when added to the main effects model $(\mathrm{p}=0.028)$. Sex, education, smoking status and number of teeth were significantly associated with the rate of change in teeth with $\mathrm{PD} \geq 4 \mathrm{~mm}$ when tested separately. The final LME model contained the main effects for all predictors and the interactions of education $(p<0.001)$, smoking status $(p=0.010)$ and toothbrushing ( $\mathrm{p}=0.029$ ) with the two time indicators. Following the LRT, the interactions for sex and number of teeth were no longer significant after the above interactions had been considered and were therefore omitted from the model. In sensitivity analysis, similar results were obtained when using data from the first (2000) and third (2011) surveys only.

Predicted mean number of teeth with $\mathrm{PD} \geq 4 \mathrm{~mm}$ were computed from the final LME model to show the rates of changes (trajectories over time) for different groups according to their education, smoking status and toothbrushing frequency (Figure 2). By 2011, the predicted mean number of teeth with $\mathrm{PD} \geq 4 \mathrm{~mm}$ was 1.19 (95\%CI: 0.55, 1.83) units higher among adults with basic than those with higher education; 2.66 (95\% CI: 2.02, 3.31) and 0.27 (95\% CI: $-0.30,0.84)$ units higher in current and former smokers than in never smokers; and 2.58 (95\%CI: 1.06, 4.09), 2.09 (95\%CI: 0.71, 3.46), and 1.90 (95\%CI: 0.51, 3.29) units lower among those brushing, respectively, more than twice, twice and once daily than among those brushing less than daily. 


\section{Discussion}

This longitudinal study found no benefit of interdental cleaning to prevent periodontal pocketing, over and above the effect of toothbrushing. Although interdental cleaning was inversely associated with periodontal pocketing in crude models, the association was fully accounted for by established risk factors for periodontal disease, which included diabetes, other behaviours (smoking, toothbrushing and dental attendance) and sociodemographic factors.

Although a negative dose-response relationship between interdental cleaning at baseline and levels of periodontal pocketing were observed at every timepoint, they become nonsignificant when potential confounders of the association were modelled. Toothbrushing and interdental cleaning were positively correlated in this sample, whereby interdental cleaning was more common among adults who brushed their teeth more often. It is therefore likely that interdental cleaning acted as a surrogate for (self-reported) toothbrushing frequency in unadjusted models. Another important confounding factor is socioeconomic position (indicated by participants' level of education in this study). There is strong evidence on the existence of social inequalities in periodontal disease (Borrell and Crawford, 2012, Schuch et al., 2017). Dental behaviours are also socially patterned as they are moulded by the circumstances where people live (Sanders et al., 2005, Singh et al., 2013). Failing to account for confounding factors and temporality between variables may explain differences with findings from three recent studies based on national cross-sectional data (Cepeda et al., 2017, Lee et al., 2018, Marchesan et al., 2018). That said, the proportion of participants reporting weekly interdental cleaning in this sample was much lower at $29.4 \%$ than that reported among American adults at 69\% (Cepeda et al., 2017, Marchesan et al., 2018), which might explain, at least partially, the present findings.

Smoking was the strongest predictor of changes in periodontal pocketing, with differences of up to 2.6 teeth with shallow pockets between current and never smokers by the end of the follow-up. Toothbrushing was inversely associated with periodontal pocketing. By the end of the follow-up, adults brushing their teeth once, twice, and more than twice daily had, on average, two teeth with pocketing less than those brushing less often than daily. Diabetes and problem-oriented visits were associated with the baseline number of teeth with pocketing, but not with its rate of change over time. To clarify, these findings suggest that diabetic adults and those visiting the dentist regularly for check-ups started the follow-up period having more teeth with pocketing, but those differences did not worsen over time. The link between 
diabetes and periodontal disease is well established (Nascimento et al., 2018). In addition, regular dental visits for check-ups might help maintaining periodontal health and controlling disease progression (Broadbent et al., 2006, Karimalakuzhiyil Alikutty and Bernabe, 2016).

Although this study found no additional benefit of interdental cleaning to the known effect of toothbrushing for the prevention of periodontal pocketing, this does not yet mean that interdental cleaning is not beneficial. Interdental cleaning could be beneficial to control disease progression among periodontal patients or for those with gingival recession (a periodontal measure not assessed in this study). Additional longitudinal studies in new settings would help corroborate and generalise these findings. Such studies should include multiple assessment of dental behaviours over time that precede full-mouth periodontal examinations. It also remains to be tested whether interdental cleaning is useful for the prevention of dental caries at proximal surfaces. For the time being, current health promotion activities at patient and population-level should focus on promoting toothbrushing behaviour (Jepsen et al., 2017, ADA, 2014, PHE/DoH, 2017, Chapple et al., 2015). What is needed is theory-driven population-based and chair-side strategies to encourage adherence to regular toothbrushing.

This study is not without limitations. First, because there were differences between those included and excluded from the study sample, the findings are not generalisable to the Finnish adult population. Second, the periodontal assessment was based on pocket depth only. Gingival recession and thus clinical attachment loss (CAL) were not assessed. PD change is not a reliable predictor of CAL (Michalowicz et al., 2013). A person could have stable levels of pocketing over time but increasing levels of recession, and therefore, periodontal disease progression (Holtfreter et al., 2015). Third, only one code (i.e. the worst condition) per tooth was recorded despite four sites per tooth being examined. As only interproximal sites would benefit from interdental cleaning, recording the deepest site per tooth (i.e. any of the four sites inspected) could have masked the association with interdental cleaning. In addition, partial-mouth recording yields lower prevalence and severity rates (Susin et al., 2005, Kingman et al., 2008, Eke et al., 2010). Fourth, interdental cleaning and toothbrushing were assessed through self-reports, which are prone to measurement error and weaker associations (Norwood et al., 2016). Misclassification of exposure could have occurred if participants reporting favourable behaviours did not have enough manual dexterity to remove plaque effectively. Although the two behaviours were validated against clinical levels of dental plaque, participants' skills and extent of cleaning were not clinically 
confirmed. Finally, although data on behaviours were collected in two surveys (2000 and 2011), we only used 2000 data to avoid reciprocal causation (also known as reverse causality or endogeneity) that could have arisen in models linking contemporaneous data about timevarying predictors and outcome (i.e. effectively converting panel data into cross-sectional data) (Singer and Willett, 2003). Therefore, our research design (regressing repeated outcome measures upon baseline exposure) was robust to control for temporality, but do not represent changes in behaviours that occur over time.

In conclusion, this longitudinal study found no association between interdental cleaning and change in periodontal pocketing among Finnish adults after accounting for well-known determinants of periodontal disease. On the contrary, toothbrushing frequency was inversely associated with change in periodontal pocketing.

\section{REFERENCES}

ADA (2014) Mouth healthy. American Dental Association.

Aromaa, A. \& Koskinen, S. (2004) Health and functional capacity in Finland. Baseline results of the Health 2000 health examination survey. Helsinki: Publications of the National Public Health Institute B12/2004. http://www.julkari.fi/handle/10024/78534.

Borrell, L. N. \& Crawford, N. D. (2012) Socioeconomic position indicators and periodontitis: examining the evidence. Periodontology 2000 58, 69-83.

Broadbent, J. M., Williams, K. B., Thomson, W. M. \& Williams, S. M. (2006) Dental restorations: a risk factor for periodontal attachment loss? Journal of clinical periodontology 33, 803-810.

Caton, J. G., Armitage, G., Berglundh, T., Chapple, I. L. C., Jepsen, S., Kornman, K. S., et al. (2018) A new classification scheme for periodontal and peri-implant diseases and conditions - Introduction and key changes from the 1999 classification. Journal of periodontology 89 Suppl 1, S1-s8.

Cepeda, M. S., Weinstein, R., Blacketer, C. \& Lynch, M. C. (2017) Association of flossing/inter-dental cleaning and periodontitis in adults. Journal of clinical periodontology 44, 866-871.

Chapple, I. L., Van der Weijden, F., Doerfer, C., Herrera, D., Shapira, L., Polak, D., et al. (2015) Primary prevention of periodontitis: managing gingivitis. Journal of clinical periodontology 42 Suppl 16, S71-76.

Eke, P. I., Thornton-Evans, G. O., Wei, L., Borgnakke, W. S. \& Dye, B. A. (2010) Accuracy of NHANES periodontal examination protocols. Journal of dental research 89, 12081213.

This article is protected by copyright. All rights reserved. 
Holtfreter, B., Albandar, J. M., Dietrich, T., Dye, B. A., Eaton, K. A., Eke, P. I., et al. (2015) Standards for reporting chronic periodontitis prevalence and severity in epidemiologic studies: Proposed standards from the Joint EU/USA Periodontal Epidemiology Working Group. Journal of clinical periodontology 42, 407-412.

Jepsen, S., Blanco, J., Buchalla, W., Carvalho, J. C., Dietrich, T., Dorfer, C., et al. (2017) Prevention and control of dental caries and periodontal diseases at individual and population level: consensus report of group 3 of joint EFP/ORCA workshop on the boundaries between caries and periodontal diseases. Journal of clinical periodontology 44 Suppl 18, S85-S93.

Joshi, S., Suominen, A. L., Knuuttila, M. \& Bernabe, E. (2018) Toothbrushing behaviour and periodontal pocketing: An 11-year longitudinal study. Journal of clinical periodontology 45, 196-203.

Karimalakuzhiyil Alikutty, F. \& Bernabe, E. (2016) Long-term regular dental attendance and periodontal disease in the 1998 adult dental health survey. Journal of clinical periodontology $43,114-120$.

Kingman, A., Susin, C. \& Albandar, J. M. (2008) Effect of partial recording protocols on severity estimates of periodontal disease. Journal of clinical periodontology 35, 659-667.

Kumar, S., Tadakamadla, J. \& Johnson, N. W. (2016) Effect of Toothbrushing Frequency on Incidence and Increment of Dental Caries: A Systematic Review and Meta-Analysis. Journal of dental research 95, 1230-1236.

Lee, J. H., Shin, Y. J., Lee, J. H. \& Kim, H. D. (2018) Association of toothbrushing and proximal cleaning with periodontal health among Korean adults: Results from Korea National Health and Nutrition Examination Survey in year 2010 and 2012. Journal of clinical periodontology 45, 322-335.

Lundqvist, A. \& Mäki-Opas, T. (2016) Health 2011 Survey - Methods. Report 8/2016. Tampere: National Institute for Health and Welfare.

Marchesan, J. T., Morelli, T., Moss, K., Preisser, J. S., Zandona, A. F., Offenbacher, S., et al. (2018) Interdental Cleaning Is Associated with Decreased Oral Disease Prevalence. Journal of dental research 97, 773-778.

Michalowicz, B. S., Hodges, J. S. \& Pihlstrom, B. L. (2013) Is change in probing depth a reliable predictor of change in clinical attachment loss? Journal of the American Dental Association (1939) 144, 171-178.

Nascimento, G. G., Leite, F. R. M., Vestergaard, P., Scheutz, F. \& Lopez, R. (2018) Does diabetes increase the risk of periodontitis? A systematic review and meta-regression analysis of longitudinal prospective studies. Acta diabetologica 55, 653-667.

Norwood, M. S., Hughes, J. P. \& Amico, K. R. (2016) The validity of self-reported behaviors: methods for estimating underreporting of risk behaviors. Annals of epidemiology 26, 612-618.e612.

Papapanou, P. N., Sanz, M., Buduneli, N., Dietrich, T., Feres, M., Fine, D. H., et al. (2018) Periodontitis: Consensus report of workgroup 2 of the 2017 World Workshop on the 
Classification of Periodontal and Peri-Implant Diseases and Conditions. Journal of periodontology 89 Suppl 1, S173-s182.

PHE/DoH (2017) Delivering better oral health: an evidence-based toolkit for prevention. London: Public Health England, Department of Health.

Poklepovic, T., Worthington, H. V., Johnson, T. M., Sambunjak, D., Imai, P., Clarkson, J. E., et al. (2013) Interdental brushing for the prevention and control of periodontal diseases and dental caries in adults. The Cochrane database of systematic reviews, Cd009857.

Salzer, S., Slot, D. E., Van der Weijden, F. A. \& Dorfer, C. E. (2015) Efficacy of inter-dental mechanical plaque control in managing gingivitis--a meta-review. Journal of clinical periodontology 42 Suppl 16, S92-105.

Sambunjak, D., Nickerson, J. W., Poklepovic, T., Johnson, T. M., Imai, P., Tugwell, P., et al. (2011) Flossing for the management of periodontal diseases and dental caries in adults. The Cochrane database of systematic reviews, Cd008829.

Sanders, A. E., Spencer, A. J. \& Stewart, J. F. (2005) Clustering of risk behaviours for oral and general health. Community dental health 22, 133-140.

Schuch, H. S., Peres, K. G., Singh, A., Peres, M. A. \& Do, L. G. (2017) Socioeconomic position during life and periodontitis in adulthood: a systematic review. Community dentistry and oral epidemiology 45, 201-208.

Singer, J. D. \& Willett, J. B. (2003) Applied Longitudinal Data Analysis: Modeling Change and Event Occurrence. Oxford: Oxford University Press.

Singh, A., Rouxel, P., Watt, R. G. \& Tsakos, G. (2013) Social inequalities in clustering of oral health related behaviors in a national sample of British adults. Preventive medicine 57, 102-106.

Suominen-Taipale, A. L., Nordblad, A., Vehkalahti, M. \& Aromaa, A. (2004) Suomalaisten Aikuisten Suunterveys, Terveys 2000-Tutkimus. Helsinki: Publications of the National Public Health Institute B16/2004. http://www.julkari.fi/handle/10024/78322.

Suominen-Taipale, A. L., Nordblad, A., Vehkalahti, M. \& Aromaa, A. (2008) Oral Health in the Finnish adult population. Health 2000 survey. Helsinki: Publications of the National Public Health Institute B 25/2008. http://www.julkari.fi/handle/10024/103030.

Susin, C., Kingman, A. \& Albandar, J. M. (2005) Effect of partial recording protocols on estimates of prevalence of periodontal disease. Journal of periodontology 76, 262-267.

Twisk, J. W. R. (2013) Applied Longitudinal Data Analysis for Epidemiology: A Practical Guide. New York, NY: Cambridge University Press.

Vernon, L. T., Da Silva, A. P. B. \& Seacat, J. D. (2017) In Defense of Flossing: Part II-Can We Agree It's Premature to Claim Flossing Is Ineffective to Help Prevent Periodontal Diseases? The journal of evidence-based dental practice 17, 149-158.

This article is protected by copyright. All rights reserved. 
Vernon, L. T. \& Seacat, J. D. (2017) In Defense of Flossing: Can We Agree It's Premature to Claim Flossing is Ineffective to Prevent Dental Caries? The journal of evidence-based dental practice 17, 71-75.

WHO (1998) Guidelines for controlling and monitoring the tobacco epidemic. pp. 76-101. Geneva.

WHO (2013) Oral health surveys - Basic methods. Geneva: WHO.

Zimmermann, H., Zimmermann, N., Hagenfeld, D., Veile, A., Kim, T. S. \& Becher, H. (2015) Is frequency of tooth brushing a risk factor for periodontitis? A systematic review and meta-analysis. Community dentistry and oral epidemiology 43, 116-127.

\section{Acknowledgments}

The Health 2000 (http://www.terveys2000.fi) and Health 2011 (http://www.terveys2011.info/) surveys were organized by the National Institute for Health and Welfare (THL), formerly the National Public Health Institute (KTL), of Finland, and partly supported by the Finnish Dental Society Apollonia, the Finnish Dental Association, and the and Unit of Oral Sciences, University of Oulu, Finland.

The authors declare no conflicts of interest in relation to this work.

Table 1. Validity of self-reports of toothbrushing and interdental cleaning frequency against clinical levels of dental plaque

\begin{tabular}{|c|c|c|c|c|c|c|c|}
\hline \multirow[t]{2}{*}{ Self-reports } & \multicolumn{2}{|c|}{ No visible plaque } & \multicolumn{2}{|c|}{$\begin{array}{l}\text { Visible plaque in } \\
\text { gingival margin }\end{array}$} & \multicolumn{2}{|c|}{$\begin{array}{c}\text { Visible plaque also } \\
\text { elsewhere }\end{array}$} & \multirow{2}{*}{$\begin{array}{l}\text { p value } \\
\text { for } \\
\text { trend }^{\mathrm{a}}\end{array}$} \\
\hline & $\mathbf{n}$ & $\%$ & $\mathbf{n}$ & $\%$ & n & $\%$ & \\
\hline Toothbrushing & & & & & & & $<0.001$ \\
\hline Less than daily & 12 & 19.4 & 32 & 51.6 & 18 & 29.0 & \\
\hline Once daily & 147 & 32.4 & 249 & 54.9 & 58 & 12.8 & \\
\hline Twice daily & 414 & 42.2 & 486 & 49.5 & 81 & 8.3 & \\
\hline More than twice daily & 69 & 42.6 & 81 & 50.0 & 12 & 7.4 & \\
\hline Interdental cleaning & & & & & & & $<0.001$ \\
\hline Never & 262 & 34.1 & 402 & 52.3 & 105 & 13.7 & \\
\hline Less than weekly & 152 & 37.9 & 215 & 53.6 & 34 & 8.5 & \\
\hline Weekly & 136 & 45.8 & 141 & 47.5 & 20 & 6.7 & \\
\hline Daily & 92 & 47.9 & 90 & 46.9 & 10 & 5.2 & \\
\hline
\end{tabular}

a Chi-squared test for linear trends was used

This article is protected by copyright. All rights reserved. 
Table 2. Toothbrushing and interdental cleaning by baseline predictors $(n=1667)$

\begin{tabular}{|c|c|c|c|c|c|c|}
\hline \multirow[t]{2}{*}{ Baseline predictors } & \multirow[t]{2}{*}{$\mathbf{n}$} & \multirow[t]{2}{*}{$\%$} & \multicolumn{2}{|c|}{$\begin{array}{c}\text { Brushing teeth } \\
\text { twice or more/day }\end{array}$} & \multicolumn{2}{|c|}{$\begin{array}{c}\text { Weekly interdental } \\
\text { cleaning }\end{array}$} \\
\hline & & & $\mathbf{n}$ & $\%$ & $\mathbf{n}$ & $\%$ \\
\hline \multicolumn{7}{|l|}{ Sex } \\
\hline Male & 748 & 44.9 & 403 & 53.9 & 133 & 17.8 \\
\hline Female & 919 & 55.1 & 742 & 80.7 & 357 & 38.9 \\
\hline$P$ value $^{a}$ & & & \multicolumn{2}{|c|}{$<0.001$} & \multicolumn{2}{|c|}{$<0.001$} \\
\hline \multicolumn{7}{|l|}{ Age groups ${ }^{b}$} \\
\hline 30-34 years & 250 & 15.0 & 177 & 70.8 & 76 & 30.4 \\
\hline $35-44$ years & 520 & 31.2 & 360 & 69.2 & 144 & 27.7 \\
\hline $45-54$ years & 490 & 29.4 & 337 & 68.8 & 156 & 31.8 \\
\hline 55-64 years & 295 & 17.7 & 192 & 65.1 & 83 & 28.1 \\
\hline $65+$ years & 112 & 6.7 & 79 & 70.5 & 31 & 27.7 \\
\hline$P$ value for trend ${ }^{a}$ & & & \multicolumn{2}{|c|}{0.351} & \multicolumn{2}{|c|}{0.620} \\
\hline \multicolumn{7}{|l|}{ Education } \\
\hline Basic & 390 & 23.4 & 229 & 58.7 & 108 & 27.7 \\
\hline Secondary & 595 & 35.7 & 383 & 64.4 & 142 & 23.9 \\
\hline Higher & 682 & 40.9 & 533 & 78.2 & 240 & 35.2 \\
\hline$P$ value for trend ${ }^{a}$ & & & \multicolumn{2}{|c|}{$<0.001$} & \multicolumn{2}{|c|}{$<0.001$} \\
\hline \multicolumn{7}{|l|}{ Diabetes } \\
\hline No & 1569 & 94.1 & 1090 & 69.5 & 464 & 29.6 \\
\hline Yes & 98 & 5.9 & 55 & 56.1 & 26 & 26.5 \\
\hline$P$ value $^{a}$ & & & \multicolumn{2}{|c|}{0.006} & \multicolumn{2}{|c|}{0.521} \\
\hline \multicolumn{7}{|l|}{ Smoking status } \\
\hline Never & 874 & 52.4 & 625 & 71.5 & 245 & 32.1 \\
\hline Former & 344 & 20.6 & 217 & 63.1 & 132 & 29.2 \\
\hline Current & 449 & 26.9 & 303 & 67.5 & 113 & 25.0 \\
\hline$P$ value for trend ${ }^{a}$ & & & \multicolumn{2}{|c|}{0.063} & \multicolumn{2}{|c|}{0.031} \\
\hline \multicolumn{7}{|l|}{ Toothbrushing frequency } \\
\hline Less than daily & 62 & 3.7 & & & 4 & 6.5 \\
\hline Once daily & 460 & 27.6 & & & 79 & 17.2 \\
\hline Twice daily & 983 & 59.0 & & & 332 & 33.8 \\
\hline More than twice daily & 162 & 9.7 & & & 75 & 46.3 \\
\hline$P$ value for trend ${ }^{a}$ & & & & & \multicolumn{2}{|c|}{$<0.001$} \\
\hline Interdental cleaning & & & & & & \\
\hline Never & 776 & 46.6 & 442 & 57.0 & & \\
\hline Less than weekly & 401 & 24.1 & 296 & 73.8 & & \\
\hline Weekly & 297 & 17.8 & 242 & 81.5 & & \\
\hline Daily & 193 & 11.6 & 165 & 85.5 & & \\
\hline$P$ value for trend ${ }^{a}$ & & & $<0$. & & & \\
\hline Dental attendance pattern & & & & & & \\
\hline Check-up & 1055 & 63.3 & 783 & 74.2 & 386 & 36.6 \\
\hline Trouble & 612 & 36.7 & 362 & 59.2 & 104 & 17.0 \\
\hline$P$ value $e^{a}$ & & & $<0$. & & $<0$. & 001 \\
\hline Number of teeth ${ }^{b}$ & & & & & & \\
\hline $1-10$ teeth & 156 & 9.4 & 92 & 59.0 & 24 & 15.4 \\
\hline $11-20$ teeth & 141 & 8.5 & 87 & 61.7 & 35 & 24.8 \\
\hline $21+$ teeth & 1370 & 82.2 & 966 & 70.5 & 431 & 31.5 \\
\hline$P$ value for trend ${ }^{a}$ & & & 0.0 & & $<0$. & 001 \\
\hline
\end{tabular}

${ }^{\text {a }}$ Chi-squared test was used for comparisons

${ }^{\mathrm{b}}$ Groups used for presentation purposes only

This article is protected by copyright. All rights reserved. 
Table 3. Number of teeth with pocketing $\geq 4 \mathrm{~mm}$ by baseline predictors

\begin{tabular}{|c|c|c|c|c|}
\hline \multirow{2}{*}{ Baseline predictors } & $2000(n=1667)$ & $2004(n=840)$ & \multicolumn{2}{|c|}{$2011(n=1031)$} \\
\hline & Mean (SD) & Mean (SD) & Mean & (SD) \\
\hline \multicolumn{5}{|l|}{$\operatorname{Sex}$} \\
\hline Male & $5.11 \quad(6.13)$ & $8.06 \quad(6.13)$ & 5.64 & $(6.39)$ \\
\hline Female & $3.14 \quad(4.73)$ & $4.96 \quad(4.84)$ & 3.73 & $(5.05)$ \\
\hline$P$ value ${ }^{a}$ & $<0.001$ & $<0.001$ & \multicolumn{2}{|c|}{$<0.001$} \\
\hline \multicolumn{5}{|l|}{ Age groups ${ }^{b}$} \\
\hline 30-34 years & $2.37 \quad(3.86)$ & $5.36 \quad(5.43)$ & & \\
\hline $35-44$ years & $3.46 \quad(5.26)$ & $6.50 \quad(5.64)$ & 3.27 & $(5.04)$ \\
\hline 45-54 years & $4.41 \quad(5.79)$ & $6.25 \quad(5.66)$ & 4.93 & $(6.31)$ \\
\hline $55-64$ years & $5.12 \quad(5.73)$ & $6.55 \quad(5.85)$ & 4.65 & $(5.68)$ \\
\hline $65+$ years & $5.74 \quad(6.39)$ & $6.25 \quad(5.66)$ & 4.68 & $(5.41)$ \\
\hline$P$ value for trend ${ }^{a}$ & $<0.001$ & 0.918 & \multicolumn{2}{|c|}{0.216} \\
\hline \multicolumn{5}{|l|}{ Education } \\
\hline Basic & $4.63 \quad(5.89)$ & $6.64 \quad(6.01)$ & 4.57 & $(5.43)$ \\
\hline Secondary & $4.58 \quad(6.02)$ & $6.63 \quad(5.41)$ & 5.66 & $(6.38)$ \\
\hline Higher & $3.19 \quad(4.60)$ & $5.89 \quad(5.69)$ & 3.82 & $(5.30)$ \\
\hline$P$ value for trend ${ }^{a}$ & $<0.001$ & 0.113 & \multicolumn{2}{|c|}{0.011} \\
\hline \multicolumn{5}{|l|}{ Diabetes } \\
\hline No & $3.90 \quad(5.37)$ & $6.30 \quad(5.66)$ & 4.58 & $(5.78)$ \\
\hline Yes & $5.95 \quad(6.87)$ & $7.38 \quad(5.87)$ & 4.74 & $(5.58)$ \\
\hline Pvalue ${ }^{a}$ & $<0.001$ & 0.170 & \multicolumn{2}{|c|}{0.848} \\
\hline \multicolumn{5}{|l|}{ Smoking status } \\
\hline Never & $3.18 \quad(4.66)$ & $5.31 \quad(5.15)$ & 3.66 & $(4.88)$ \\
\hline Former & $4.09 \quad(5.29)$ & $6.18 \quad(4.92)$ & 4.39 & $(5.53)$ \\
\hline Current & $5.38 \quad(6.61)$ & $8.17 \quad(6.60)$ & 6.48 & $(6.94)$ \\
\hline$P$ value for trend ${ }^{a}$ & $<0.001$ & $<0.001$ & & 001 \\
\hline Toothbrushing frequency & & & & \\
\hline Less than daily & $6.35 \quad(7.16)$ & $10.74 \quad(7.01)$ & 8.59 & $(9.25)$ \\
\hline Once daily & $4.15 \quad(5.77)$ & $6.64 \quad(5.65)$ & 5.53 & $(6.25)$ \\
\hline Twice daily & $3.89 \quad(5.22)$ & $6.15 \quad(5.49)$ & 4.18 & $(5.32)$ \\
\hline More than twice daily & $3.58 \quad(5.38)$ & $5.02 \quad(5.39)$ & 3.33 & $(4.83)$ \\
\hline$P$ value for trend ${ }^{a}$ & 0.005 & $<0.001$ & & 001 \\
\hline Interdental cleaning & & & & \\
\hline Never & $4.66 \quad(6.06)$ & $6.87 \quad(5.99)$ & 5.37 & $(6.30)$ \\
\hline Less than weekly & $3.35 \quad(4.66)$ & $6.34 \quad(5.48)$ & 4.38 & $(5.68)$ \\
\hline Weekly & $3.45 \quad(4.95)$ & $5.83 \quad(5.42)$ & 3.80 & $(5.12)$ \\
\hline Daily & $3.73 \quad(5.19)$ & $4.90 \quad(4.62)$ & 3.69 & $(4.70)$ \\
\hline$P$ value for trend ${ }^{a}$ & 0.001 & 0.001 & & 01 \\
\hline Dental attendance pattern & & & & \\
\hline Check-up & $3.73 \quad(5.08)$ & $6.06 \quad(5.58)$ & 4.12 & $(5.32)$ \\
\hline Trouble & $4.53 \quad(6.11)$ & $6.87 \quad(5.81)$ & 5.45 & $(6.43)$ \\
\hline$P$ value for trend ${ }^{a}$ & 0.004 & 0.045 & & 001 \\
\hline Number of teeth ${ }^{b}$ & & & & \\
\hline $1-10$ teeth & $1.37 \quad(2.25)$ & $2.38 \quad(2.53)$ & 2.08 & $(2.48)$ \\
\hline 11-20 teeth & $4.15 \quad(4.71)$ & $5.31 \quad(4.54)$ & 5.17 & $(5.05)$ \\
\hline $21+$ teeth & $4.31 \quad(5.74)$ & $6.98 \quad(5.87)$ & 4.84 & $(6.07)$ \\
\hline$P$ value for trend ${ }^{a}$ & $<0.001$ & $<0.001$ & & 001 \\
\hline
\end{tabular}

${ }^{a}$ t-test and analysis of variance were used to compare 2 and 3+ groups, respectively

${ }^{\mathrm{b}}$ Groups used for presentation purposes only

This article is protected by copyright. All rights reserved. 
Table 4. Linear mixed effects (LME) models for the association between baseline predictors and number of teeth with pocketing $\geq 4 \mathrm{~mm}$ over 11 years $(n=1667)$

\begin{tabular}{|c|c|c|c|c|}
\hline \multirow[t]{2}{*}{ Baseline predictors } & \multicolumn{2}{|c|}{ Model with main effects } & \multicolumn{2}{|c|}{$\begin{array}{c}\text { Model with main effects } \\
\text { and interactions }\end{array}$} \\
\hline & Coef. & {$[95 \% \mathrm{CI}]$} & Coef. & {$[95 \% \mathrm{CI}]$} \\
\hline Age $^{a}$ (centred at mean) & 0.12 & {$[0.10,0.14]^{* * *}$} & 0.07 & {$[-0.03,0.16]$} \\
\hline Survey (reference: no) & 2.09 & {$[1.74,2.43]^{* * *}$} & 3.18 & {$[1.37,4.98]^{* *}$} \\
\hline \multicolumn{5}{|l|}{ Sex (reference: Male) } \\
\hline Female & -1.47 & {$[-1.92,-1.02]^{* * *}$} & -1.45 & {$[-1.90,-1.00] * * *$} \\
\hline \multicolumn{5}{|l|}{ Education (reference: Basic) } \\
\hline Secondary & -0.23 & {$[-0.81,0.35]$} & -0.72 & {$[-1.41,-0.03]^{*}$} \\
\hline Higher & -1.35 & {$[-1.95,-0.76] * * *$} & -2.02 & {$[-2.72,-1.33] * * *$} \\
\hline \multicolumn{5}{|l|}{ Diabetes (reference: non-diabetic) } \\
\hline Diabetic & 0.94 & {$[0.04,1.84]^{*}$} & 0.89 & {$[0.00,1.79]^{*}$} \\
\hline \multicolumn{5}{|l|}{ Smoking status (reference: Never) } \\
\hline Former & 0.31 & {$[-0.2,0.82]$} & 0.25 & {$[-0.32,0.81]$} \\
\hline Current & 2.42 & {$[1.92,2.92]^{* * *}$} & 2.07 & {$[1.52,2.62]^{* * *}$} \\
\hline \multicolumn{5}{|c|}{ Toothbrushing (reference: Less than daily) } \\
\hline Once daily & -2.20 & {$[-3.33,-1.08]^{* * *}$} & -1.69 & {$[-2.94,-0.44] * *$} \\
\hline Twice daily & -2.22 & {$[-3.34,-1.10]^{* * *}$} & -1.61 & {$[-2.84,-0.37]^{*}$} \\
\hline More than twice daily & -2.77 & {$[-4.05,-1.48] * * *$} & -1.97 & {$[-3.41,-0.52]^{* *}$} \\
\hline \multicolumn{5}{|l|}{ Interdental cleaning (reference: Never) } \\
\hline Less than weekly & -0.66 & {$[-1.34,0.02]$} & -0.61 & {$[-1.30,0.08]$} \\
\hline Weekly & -0.45 & {$[-1.05,0.14]$} & -0.46 & {$[-1.06,0.13]$} \\
\hline Daily & -0.59 & {$[-1.30,0.11]$} & -0.62 & {$[-1.33,0.08]$} \\
\hline \multicolumn{5}{|c|}{ Dental attendance pattern (reference: For check-ups) } \\
\hline Only when in trouble & 1.06 & {$[0.62,1.51]^{* * *}$} & 1.10 & {$[0.66,1.55]^{* * *}$} \\
\hline Number of teeth (centred at mean) & 0.29 & {$[0.25,0.33]^{* * *}$} & 0.29 & {$[0.25,0.33]^{* * *}$} \\
\hline \multicolumn{5}{|c|}{ Age (centred at mean) X Education (reference: Basic) } \\
\hline Secondary & & & 0.07 & {$[0.03,0.12]^{* *}$} \\
\hline Higher & & & 0.06 & {$[0.02,0.11]^{* *}$} \\
\hline \multicolumn{5}{|c|}{ Survey (reference: no) X Education (reference: Basic) } \\
\hline Secondary & & & 0.00 & {$[-0.88,0.88]$} \\
\hline Higher & & & 0.72 & {$[-0.18,1.61]$} \\
\hline \multicolumn{5}{|c|}{ Age (centred at mean) X Smoking status (reference: Never) } \\
\hline Former & & & 0.00 & {$[-0.04,0.04]$} \\
\hline Current & & & 0.03 & {$[-0.01,0.07]$} \\
\hline \multicolumn{5}{|c|}{ Survey (reference: no) X Smoking status (reference: Never) } \\
\hline Former & & & 0.25 & {$[-0.59,1.10]$} \\
\hline Current & & & 1.00 & {$[0.18,1.82]^{*}$} \\
\hline \multicolumn{5}{|c|}{ Age (centred at mean) X Toothbrushing frequency (reference: Less than daily) } \\
\hline Once daily & & & 0.02 & {$[-0.08,0.11]$} \\
\hline Twice daily & & & -0.01 & {$[-0.10,0.09]$} \\
\hline More than twice daily & & & 0.00 & {$[-0.11,0.10]$} \\
\hline \multicolumn{5}{|c|}{ Survey (reference: no) X Toothbrushing (reference: Less than daily) } \\
\hline Once daily & & & -1.63 & {$[-3.45,0.18]$} \\
\hline Twice daily & & & -1.73 & {$[-3.50,0.04]$} \\
\hline More than twice daily & & & -2.43 & {$[-4.44,-0.41]^{*}$} \\
\hline
\end{tabular}

a Participants' age was assessed in years and centred at mean age at baseline. The coefficient represents the increment in teeth with pocketing $>4 \mathrm{~mm}$ for every year increase in age.

${ }^{\mathrm{b}}$ Only significant interactions were included in the final model. Interactions were tested by contrasting nested models (with and without the interaction term) via the likelihood ratio test. $* \mathrm{p}<0.05, * * \mathrm{p}<0.01, * * * \mathrm{p}<0.001$ 


\section{Figures legend}

Figure 1. Participation flowchart and data linkage for the Health 2000 Survey, the 2004/05 Follow-Up Survey of Adults' Oral Health and the Health 2011 Survey.

Figure 2. Predicted number of teeth with pocketing $\geq 4 \mathrm{~mm}$ according to education, smoking status, toothbrushing frequency and interdental cleaning. Predicted means were derived from the linear mixed effect model presented in Table 4.
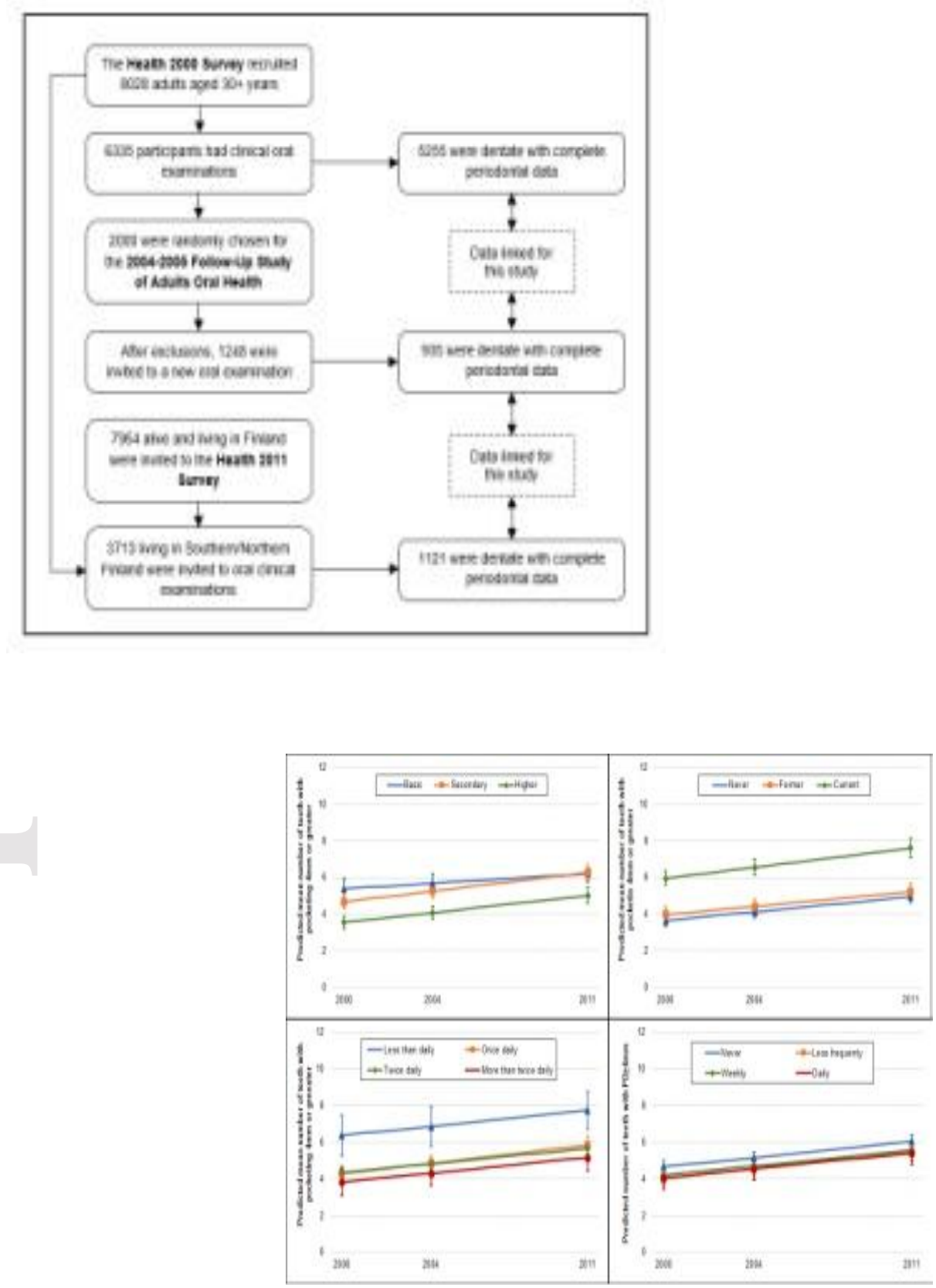

This article is protected by copyright. All rights reserved. 